\title{
A History of Numerical Weather Prediction
}

\author{
By F. H. Bushby \\ Meteorological Office, Bracknell, England \\ (Manuscript received 20 October 1986, in revised form 15 January 1987)
}

\begin{abstract}
This paper covers the principal milestones in Numerical Weather Prediction from the "beginning" to the present day and is divided into three main sections. First the beginning which, in my view, was L.F. Richardson's (1922) book on Weather Prediction by Numerical Processes following some earlier work by Bjerknes. The second section is devoted to the theoretical and practical studies which were started by Charney and his colleagues at Princeton University at the end of World War II with the advent of electronic computers and which have continued in many centres up to the present day. The final section deals with the introduction of NWP into operational forecasting and some personal reminiscences of those involved in the early days.
\end{abstract}

\section{Introduction}

In a 30 minute lecture it is not possible to do justice to all those who have made contributions to the development of NWP, let alone those who have contributed in lesser ways. It should therefore be noted that this is " $\mathrm{A}$ " rather than "THE" history of NWP. In deciding what material to include I have tried to give a balanced overall view of both the scientific achievements and the introduction of NWP into operational weather forecasting. Whilst there has never been any difficulty in getting papers published which have shown new scientific advances, the development of robust operational schemes entailing much ingenuity and hard work has often gone unrewarded and this paper makes some attempt to re-dress the balance.

\section{The begining}

At the beginning of the twentieth century Bjerknes, the famous Norwegian meteorologist, was one of the first to consider forecasting the weather according to the dynamics and physics of the atmosphere. Quite independently in 1911, L. F. Richardson who had already been interested in finite diferences, began to dream of a forecast factory in which several thousand people would compute the weather. Once Richardson became aware of the Bjerknes work it had a considerable influence on his subsequent activities.

Due to interruptions during the war years, several revisions and problems with funding, it was 11 years before Richardson's (1922) now famous book on Weather Prediction by Numerical Process was published. He was a most interesting person and Ashford (1985) has written his biography. Richardson's book is remarkable on two accounts. He was one of the first to set out the fundamental equations of the dynamics and physics of the atmosphere in a systematic way and he produced a series of computing forms suitable for the numerical solution of those fundamental equations.

Richardson developed a set of partial differential equations for predicting pressure, temperature, horizontal and vertical velocity and moisture taking into account radiation, the effects of cloud and precipitation, eddy motion, friction, topography and exchanges 
of energy between the ground and the atmosphere which even included variations due to vegetation and state of ground. The consideration of these physical processes was most thorough and exhaustive. It is of interest that when the first realistic numerical integrations were carried out more than 20 years later they were purely dynamic; no physical processes being included. Indeed, it is only during the last 15 years that electronic computers have become fast enough to allow sophisticated treatment of physical processes to be gradually introduced into NWP models, although this was done somewhat earlier in GCM models where computational time was not critical.

In order to carry out the numerical integration of his prognostic equations, Richardson used latitude, longtitude, height above mean sea level and time as the independent variables. $\mathrm{He}$ endeavoured to maintain a nearly square horizontal grid and discussed problems arising because of the polar cap and even considered the advantages of what is now known as a "sigma" coordinate system in the vertical. Although height was even- tually used as the vertical coordinate, he choose his levels to be such as to allow the strata to contain approximately the same mass. His model contained 5 layers 6 levels at approximately $200 \mathrm{mb}$ intervals) and the horizontal grid was about $200 \mathrm{~km}$ although pressure, temperature and humidity alternated with momentum in the horizontal, making an effective grid length of $400 \mathrm{~km}$. His consideration in depth of the choice of coordinate system is another example of how far ahead of his time Richardson was.

He quickly realised that in order to keep ahead of the weather he would need a very large number of people working on different parts of the map. He therefore produced a most methodical system of 23 computing forms to allow the calculations to proceed speedily and accurately. An example is the form to calculate the pressure tendency given in Fig. 1. The result of a forecast $145 \mathrm{mb}$ pressure change in 6 hours was a glaring error, as in fact the barometer was steady. This error was attributed mainly to a large spurious convergence of thein itial winds although it later became clear that there had been an

COMPUTING FORM P XIII. Divergence of horizontal momentum-per-area. Increase of pressure The equation is typified by: $-\frac{\partial R_{86}}{\partial t}=\frac{\partial M_{E B 6}}{\partial e}+\frac{\partial M_{\text {NBG }}}{\partial n}-M_{\text {NB6 }} \frac{\tan \phi}{a}+m_{H G}-m_{H B} \theta^{*}+\frac{2}{a} M_{H B G}$. (See Ch. 4/2\#5.)

- In the equation for the lowest stratum the corresponding term - $m_{G B}$ does not appear

\begin{tabular}{|c|c|c|c|c|c|c|c|c|c|c|c|c|}
\hline & & \multicolumn{2}{|c|}{$\begin{array}{l}\text { Longitude } 11^{\circ} \text { east } \\
\delta \mathrm{e}=441 \times 10^{5}\end{array}$} & \multicolumn{3}{|c|}{$\begin{array}{l}\text { Latitude } 5400 \mathrm{~km} \text { north } \\
\qquad \delta \mathrm{n}=400 \times 10^{5}\end{array}$} & \multicolumn{3}{|c|}{$\begin{array}{c}\text { Instant } 1910 \text { May } 20^{\circ} 7^{\mathrm{n}} \text { GMT } \\
\mathrm{a}^{-1} \cdot \tan \phi=1.78 \times 10^{-9}\end{array}$} & \multicolumn{3}{|c|}{$\begin{array}{c}\text { Interval, } \delta t 6 \text { hours } \\
a=6.36 \times 10^{8}\end{array}$} \\
\hline Ref:- & & & & \begin{tabular}{|l|} 
previous \\
3 columns \\
\end{tabular} & $\begin{array}{l}\text { previous } \\
\text { column }\end{array}$ & & Form $P$ XVI & Form PXVI & $\begin{array}{l}\text { equation } \\
\text { above }\end{array}$ & $\begin{array}{l}\text { previous } \\
\text { column }\end{array}$ & $\begin{array}{l}\text { previous } \\
\text { column }\end{array}$ & $\begin{array}{l}\text { previous } \\
\text { column }\end{array}$ \\
\hline $\mathrm{h}$ & $\frac{\delta \mathrm{M}_{\mathrm{E}}}{\delta \mathrm{e}}$ & $\frac{\delta M_{v}}{6 n}$ & $\frac{M_{N} \tan \phi}{a}$ & divenM & - got div' ${ }_{\mathrm{ENM}}$ & & $m_{11}$ & $\frac{2 M_{11}}{a}$ & $\frac{\partial R}{\partial t}$ & $+\frac{\partial R}{\partial t} \delta t$ & $g \frac{\partial A}{\partial t} \delta t$ & $\frac{\partial p}{\partial t} \delta t$ \\
\hline & $10^{-3} x$ & $10^{-5} x$ & $10^{-5} x$ & $10^{-3} x$ & $100 x$ & \multirow{2}{*}{ 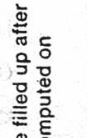 } & $10^{-3} x$ & $10^{-3} x$ & $10^{-5} x$ & & $100 x$ & $100 x$ \\
\hline$n_{0}$ & -61 & -245 & -6 & -312 & 656 & & -83 & & -229 & 49.5 & 483 & 0 \\
\hline & 367 & -257 & 2 & 112 & -236 & ن & & 0.06 & -136 & 29.4 & 287 & 483 \\
\hline$h_{4}$ & \multirow{2}{*}{93} & \multirow{2}{*}{-303} & \multirow{2}{*}{-16} & \multirow{2}{*}{-226} & & 茴 & 165 & & & & & 770 \\
\hline$h_{6}$ & & & & & 410 & 궁 & 63 & 0.11 & -124 & 20.8 & 202 & 1032 \\
\hline$h_{9}$ & 32 & -55 & -12 & -35 & 74 & 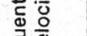 & & 0.07 & -110 & 23.8 & 233 & \\
\hline & -256 & 38 & +8 & -226 & 479 & 㟧 & & 0.03 & -88 & 19.0 & 186 & \\
\hline 116 & & $\begin{array}{l}: \mathrm{div}_{\mathrm{EN} N} \\
\frac{\delta \mathrm{M}_{\mathrm{E}}}{\delta \mathrm{e}}+\end{array}$ & contrac & tion for & $\begin{array}{c}\text { SUM }= \\
1451 \\
=\frac{\partial p_{G}}{\partial t} \delta t\end{array}$ & 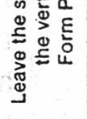 & & & & & & $\begin{array}{c}\text { check by } \\
\Sigma-g \delta t^{\prime} \text { div'ENM }\end{array}$ \\
\hline
\end{tabular}

Fig. 1 Calculation of pressure tendency 
infringement of the Courant-Friedricks-Levy stability criterion.

\section{Further developments}

The matter then lay almost dormant until the advent and availability of electronic computers at the end of World War II, although Rossby $(1939,1940)$ was developing the use of the vorticity equation and Sutcliffe (1947) the concept of development using thickness patterns; two ideas which were to play an important role in subsequent events.

The setting up of a Meteorological Research Group at the Institute of Advanced Study, Princeton, under Jule Charney, to consider the application of electronic computers to dynamic weather prediction was probably the most important single step in the history of the subject. The concept of a non-divergent level in mid-troposphere where the absolute vorticity would be conserved, together with the filtering out of troublesome gravity waves from the vorticity equations by the geostropic approximation, led to the computation of the first barotropic forecast. The computation time was almost exactly the same as the atmosphere took to achieve a similar result and the experiment is reported in detail in a very important paper by Charney, Fjortoft and von Neumann (1950). The results of this 24 hour barotropic forecast are shown in Fig. 2. It can be seen that the north-eastward movement, but not the deepening, of the $500 \mathrm{mb}$ vortex over the central U.S. A. was forecast, as was the build up of pressure over and to the west of Oregon. This was most encouraging. It showed, in contrast to Richardson's earlier attempt, that NWP was now both possible and practical and led to the formation of many research groups throughout the world which have resulted in the excellent standard of today's products.

The development of the so-called filtered models progressed rapidly. Baroclinicity was introduced by two different approaches; the superimposition of several barotropic layers on the one hand and the adaptation of development theory on the other. Problems relating to the divergence of the geostrophic wind were overcome by the use of a stream function and empirical methods were developed for counteracting the spurious retrogression of the long waves. Methods of parameteriz-

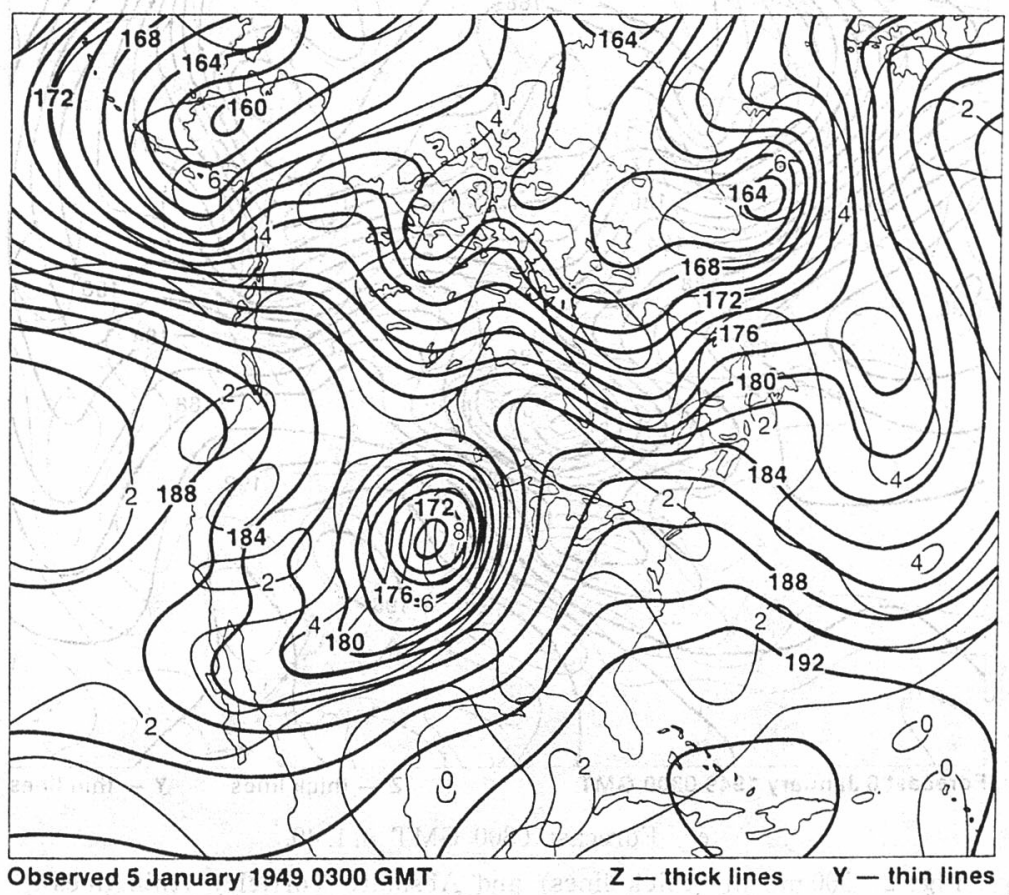

a. Actual 0300 GMT 5.1.49 


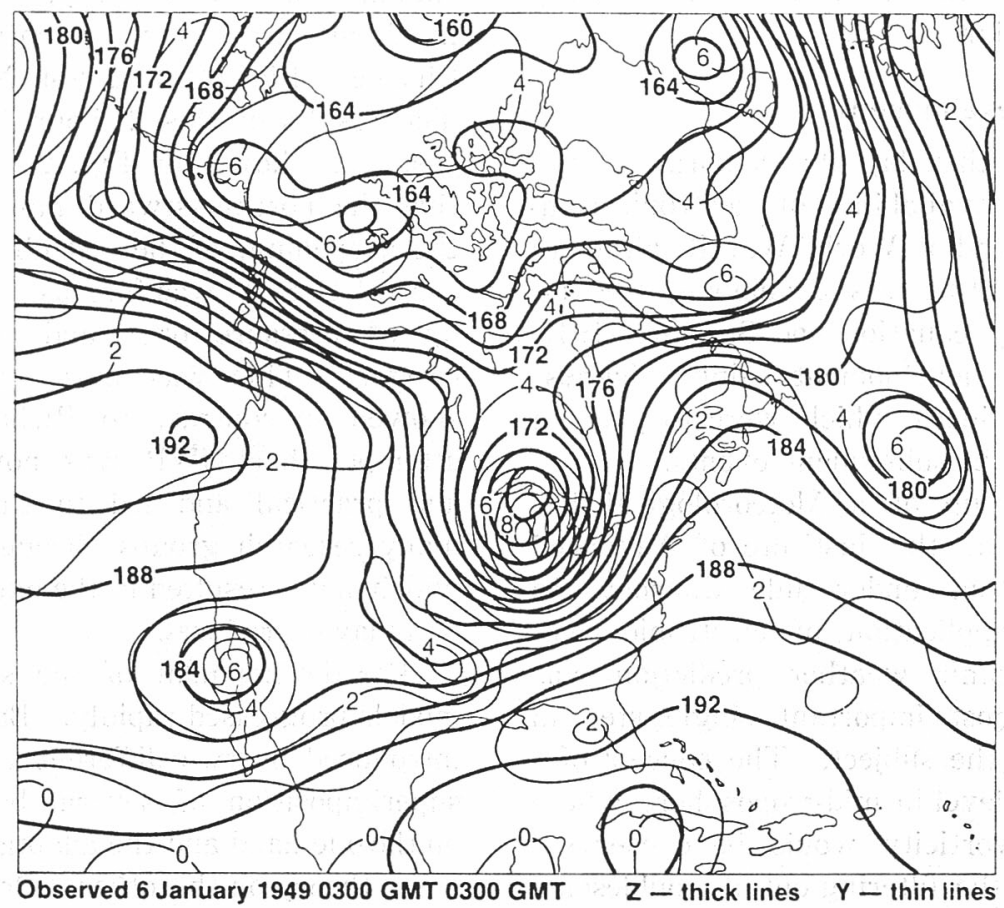

b. Actual 0300 GMT 6.1.49

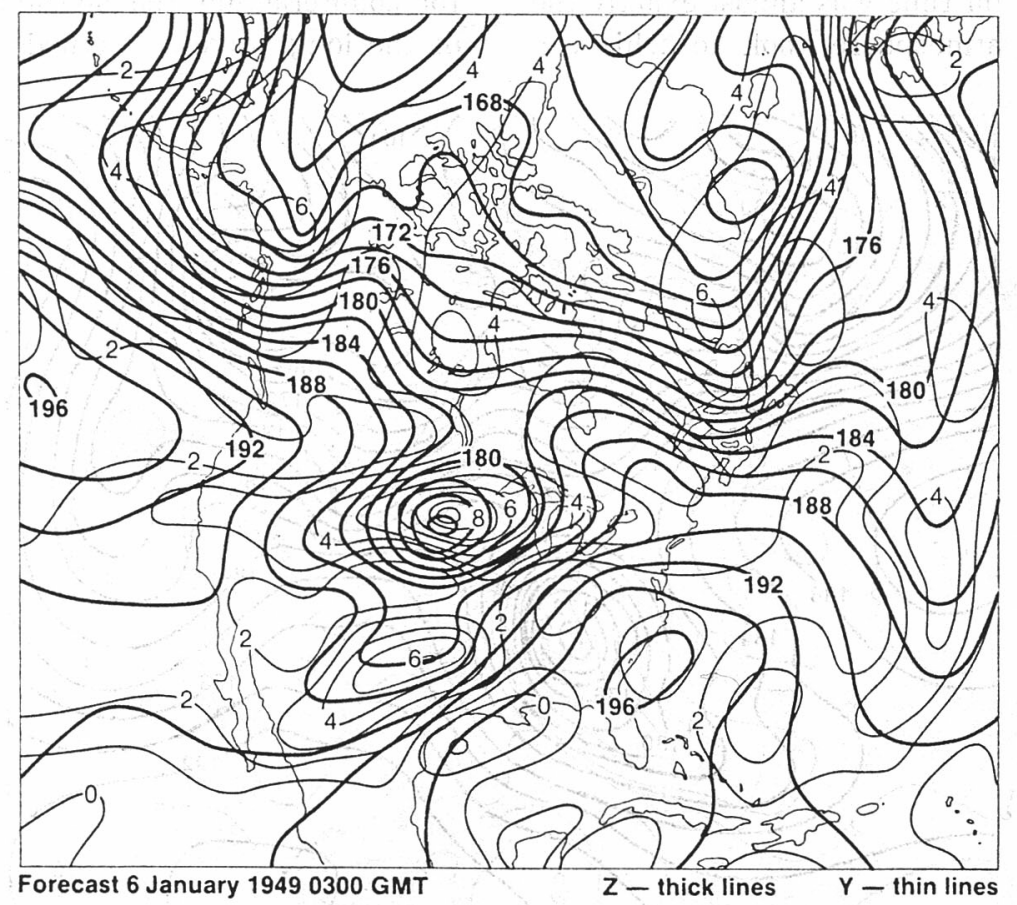

c Forecast 0300 GMT 6.1.49.

Fig. $2500 \mathrm{mb}$ ht (thick lines) and Absolute Vorticity (thin lines) 
ing physical processes such as surface friction, topography and non-adiabatic heating were gradually introduced. It is of interest to note that Cressman and Hubert (1957) showed that systematic errors caused by the divergence of the geostrophic wind could be almost eliminated by the use of a stream function and that it was essential to remove those errors before other errors in the treatment of baroclinic development and nonadiabatic effects could be isolated and resolved.

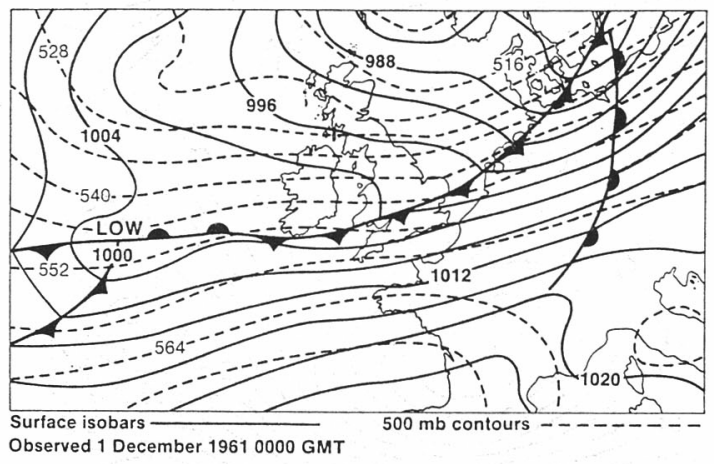

(a)

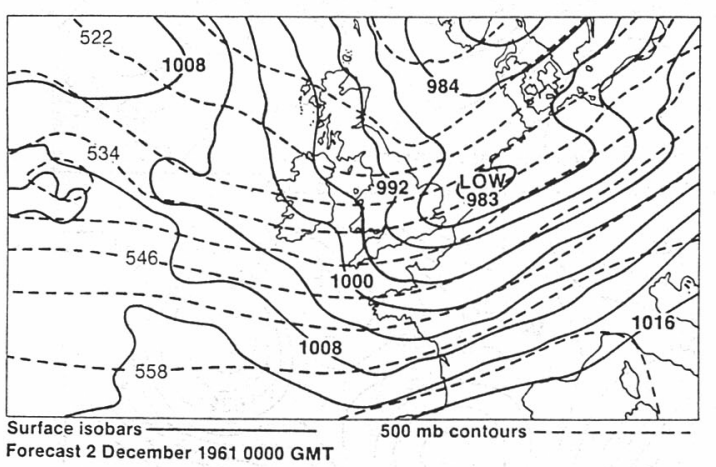

(c)

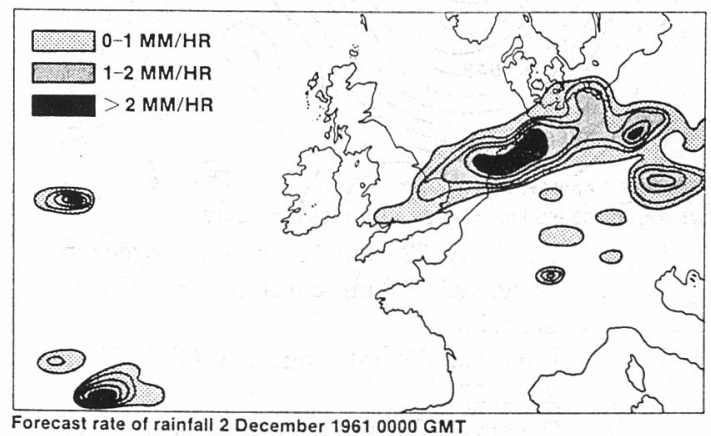

(e)
However, the speed of electronic computers was rapidly increasing and in the 1960s one could envisage being able to use a time step sufficiently short to ensure computational stability of the non-filtered (primitive) equations of motion and still compute the forecast in time to be of use. Charney (1955) had already demonstrated that if the initial wind and pressure fields were adjusted to eliminate the troublesome initial divergence, a satisfactory forecast could be produced by using

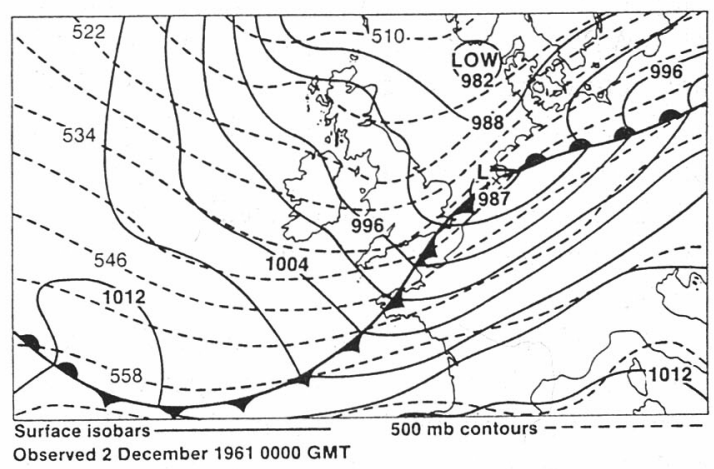

(b)

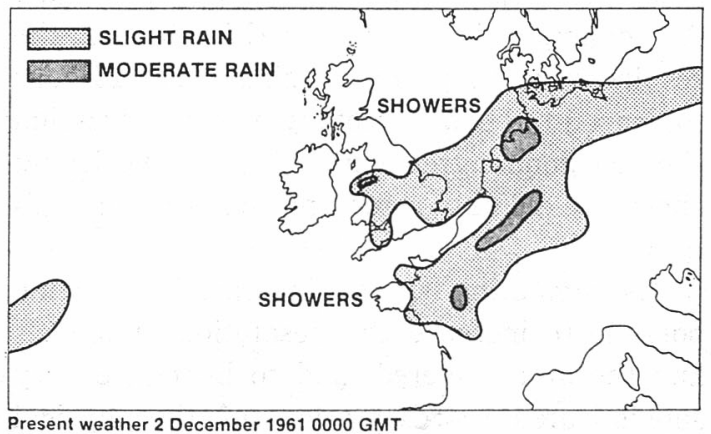

(d)

Fig. 3 a. Observed pressure 0000 GMT 1.12.61 b. Observed pressure 0000 GMT 2.12.61

c. Forecast pressure 0000 GMT2.12.61

d. Present weather 0000 GMT 2.12.61

e. Forecast rate of rainfall 0000 GMT 2. 12.61 . 
the non-filtered equations. Eliasson (1956), Smagorinsky (1958), Hinkelmann (1959), Shuman (1962) and Bushby and Timpson (1967) all made significant contributions to the development of multi-level primitive equation models. Since then, as computers became faster, horizontal and vertical resolutions were increased and it has been possible to represent the physics in a more realistic manner.

The Oriental influence was quite marked at that time as several eminent Japanese meteorologists moved to the U.S.A. and played a prominent role in the development of NWP. Arakawa's (1966) work on grid and convection schemes, Kasahara's (1965) on finite difference methods, Manabe's (1956) on thermodynamic effects and Miyakoda's (1982) on extended range predictions are a few examples of the contributions that were made.

One of the first attempts to predict weather, as distinct from pressure patterns and . vertical velocity fields was made by Bushby and Timpson (1967). A 10 level limited area primitive equation model was used with variables represented at $100 \mathrm{~km}$ intervals. An example is shown in Fig. 3 and the results were very encouraging. The 24 hour forecast of the fast moving wave depression showed good agreement with the verifying chart, as did the rates and areas of precipitation.

As computing speeds increased it became possible to increase the resolution of models and the area covered, and to introduce very sophisticated representations of the physical processes. This has led to the present "state of the art" which will be described in other papers being given at this Symposium.

\section{Introduction into operational use}

The first "real time" forecasts on a regular. basis were produced by the Swedish Military Weather Service in 1954, in close cooperation with Rossby's group at the Meteorological Institute of Stockholm. They were in the nature of field trials and, after a second trial including an objective analysis scheme, it was decided that an NWP system was to be adopted as a basic operational feature from 1.10.56.
These first operational forecasts have been described by Bergthorsson, Döös, Fryklund, Haug and Lindquist (1955) and by Herrlin
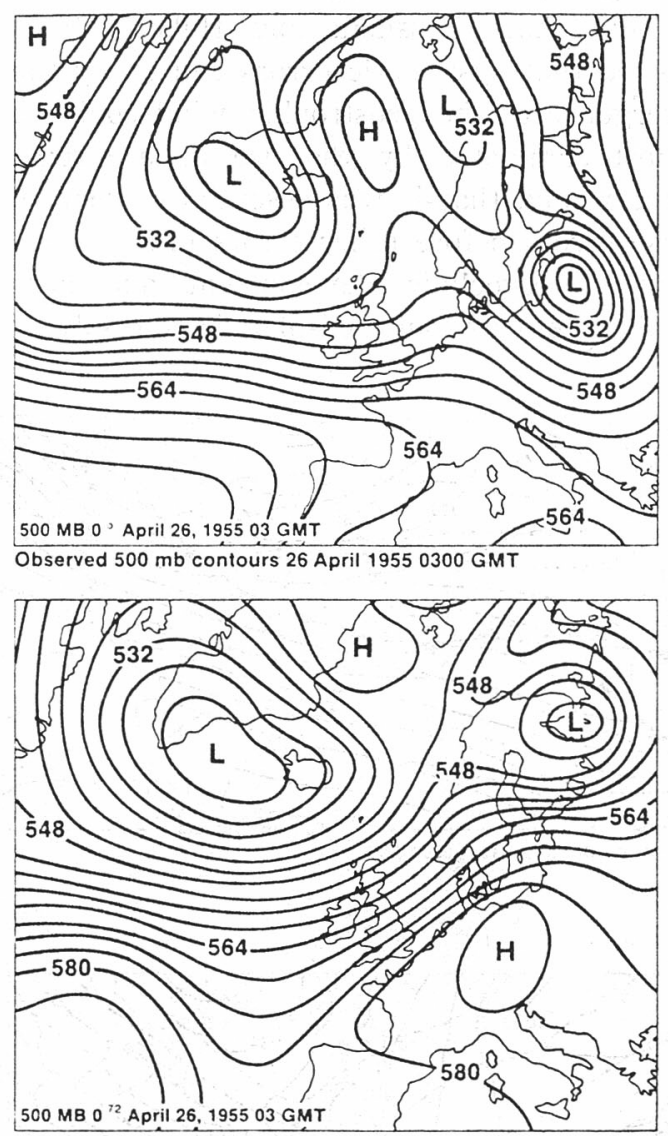

(b)

72 hour forecast for 29 April 19550300 GMT

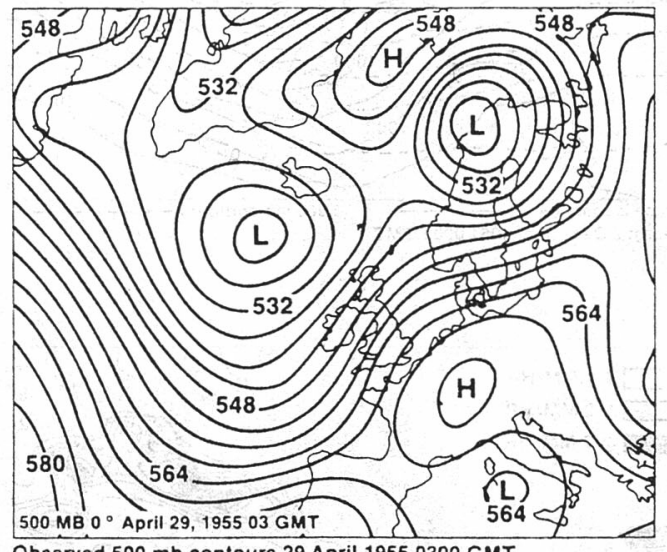

Observed 500 mb contours 29 April 19550300 GMT

Fig. 4 An early 72 hour barotropic forecast

a Observed $500 \mathrm{mb}$ contours $0300 \mathrm{GMT}$ 26. 4.55

b. Forecast $500 \mathrm{mb}$ contours $0300 \mathrm{GMT}$ 29. 4.55

c. Observed $500 \mathrm{mb}$ contours 0300 GMT 29.4.55. 
(1956). An example of a 72 hour forecast is shown in Fig. 4. There was very encouraging agreement between the forecast and the observed situation. I think it is of interest to include the following extract from a letter to me from Col. Soderberg who is at present in charge of the Swedish Military Weather Service "...The operational tests 1.12.5424.5.55 were carried out in close co-operation with the Meteorological Institute of Stockholm University. As a matter of fact the friendship between Rossby and Herrlin probably was an important factor in the early start of the project. Rossby, eager to put his theories to the test, and Herrlin, realising the operational potential of the new methods, found it easy to co-operate and both were willing to take risks to promote the development they visualised. It is probably fair to say that Rossby's and Herrlin's personal involvement and enthusiasm had a significant impact and convinced all those involved that they were doing a meaningful job. There was a lot of extra work and few to do it; analysis, gridding, punching, preparations at BESK and re-runs when BESK decided to take a rest (which happened frequently). The maintenance engineer would then start punching each of the 2400 valves with a felt hammer until the fault was cured. If that did not cure the fault he had to find the valve due for replacement. After a run there was also the plotting of grid values, analysis and interpretation of results...". Col. Herrlin received the Legion of Merit on a visit to the U.S. in 1960 as a recognition for a pioneering contribution in the process of introducing NWP as a basic element in operational weather forecasting.

Although operational NWP was not introduced in the Federal Republic of Germany until 1966, the following comments sent me by Dr. Edelmann are worthy of note and are typical of the early days in many centres. "...While the first computers in the U.S.A. produced filtered barotropic forecasts, Hinkelmann felt the necessity to incorporate the vertical structure of the atmosphere by more than a second level. Beginning in late Autumn of 1952 he tried to make forecasts using a three-dimensional quasi-geostrophic model with 3 and later with 4 levels. However, there was no computer available! How to solve the task? The very provisional circumstances in the FRG after the war should be mentioned. The place of the story was narrow rooms under the sloping roof of an old hotel, full of cigarette smoke, a blackboard completely covered with hieroglyphics, and chalk dust everywhere. Hinklemann's mini-group consisting of one or two students and two girls (among them the now-President of the German Weather Service and his wife) started with the following procedure: After the initial analyses had been manually prepared by the synoptic division, the vorticity and the Jacobians of the quasi-geostrophic model were evaluated by graphical methods-a big lot of maps and a work of several days! Then grid point values had to be interpolated, read out and written very small on a huge paper covering a whole blackboard for the main step of the work, namely the solution of the threedimensional elliptic equations for the tendency by relaxation. One girl read out the figures of the difference operator to the other, who sat at a very heavy noisy, slow mechanical calculator. She called the result back to the first girl. So it went on from grid point to grid point, from row to row. After a couple of hours, the girls changed their places, after a couple of days they had done an iteration for the whole field, and after several weeks they got figures we assumed to be the solution of the elliptic equation. The tendency was converted back to a map and graphically added to the initial field, giving us a $12 \mathrm{hr}$ forecast. Then the entire procedure was repeated to give us a 24 -hr prediction. The result of some months of stupid work did not look totally unreasonable. We never dreamt that 30 years later all this computation would be much better performed within a few seconds".

In the United Kingdom Meteorological Office the early days of development of NWP in the Forecast Research Division at Dunstable followed a similar pattern to that in the FRG. No computer was available at first 


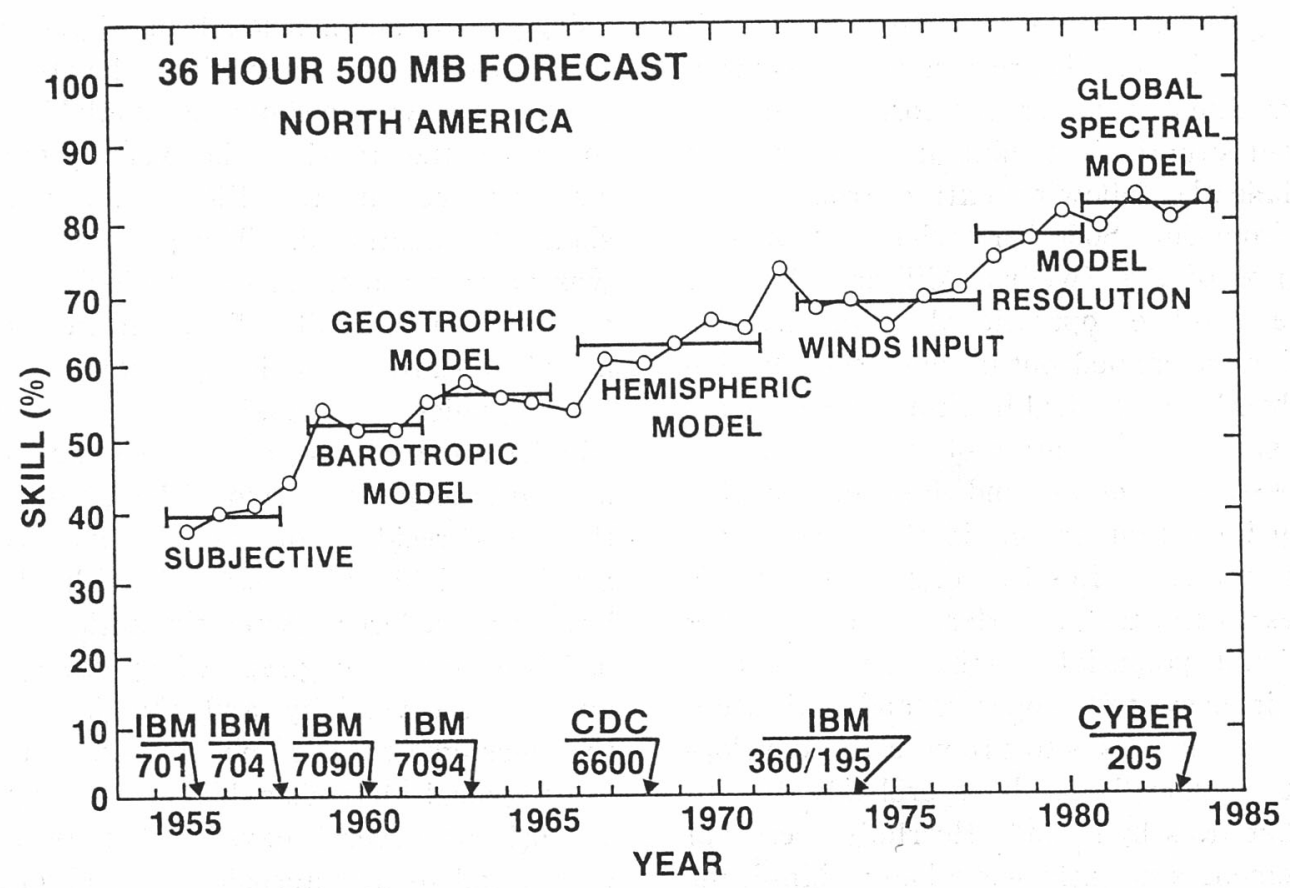

Fig. 536 Hour $500 \mathrm{mb}$ forecasts at NMC

and lengthy tedious hand computations had to be performed. One of the girls involved in these computations has written (Hinds 1981) a history of NWP in the UK. We were eventually able to use computers at Joe Lyons and Co (a food company) and then at Manchester University before our own Mercury computer was delivered in 1959. Eventually our first operational numerical forecast (3 level baroclinic quasi-geostrophic) was produced in 1965 and a 10 level PE model was introduced in 1972. In 1954, at about the same time that the field trials were starting in Sweden, the Joint Numerical Weather Prediction Unit was formed in Washington by the United States Weather Bureau, Air Weather Service and Naval Aerological Service. Daily forecasts (3 level, quasi-geostrophic, limited area) were produced by this unit from 1955 onwards, although it is generally accepted that the first useful operational system did not exist until 1959 when a quasi-hemispheric barotropic model with long-wave stabilization was introduced. Fig. 5 is a schematic representation of the improvement in skill of the $500 \mathrm{mb}$ forecasts at NMC when improvements were made to the operational scheme as greater computing power became available. In Canada, not wishing to duplicate the products produced by NMC, early data cut-off times have been used allowing hemispheric forecasts to be produced much earlier than from NMC, albeit from incomplete data. However, NMC have now introduced an early cut-off run in addition to their main runs.

Operational NWP in the Southern Hemisphere was introduced in Australia in 1969 using a limited area quasi-geostrophic barotrophic model. Sparsity of data meant that manual controls needed to be used in the analysis systems but the forecasts were quickly accepted and replaced the manual prognosis. The complexity of the model was gradually increased and the first hemispheric operational forecast were produced in 1973.

Finall, I would like to mention the introduction of NWP by the Host Nation of this Symposium. A Northern Hemisphere Barotrophic Model was introduced in June 1959 and a 3-level balanced model was in troduced in 1970. Primitive equations were introduced in 1975 and the current operational hemispheric model is 12-level spectral (T42) PE. 
Limited area (Asian) models were introduced in 1960, leading to a 12 -level PE $127 \mathrm{~km}$ grid being introduced in March 1973 and a 13-level model $(64 \mathrm{~km})$ in November 1984 . A Moving Nested Grid Typhoon Forecast Model was introduced in March 1982.

\section{Conclusions}

It has not been possible to mention all the Centres where NWP has been developed nor

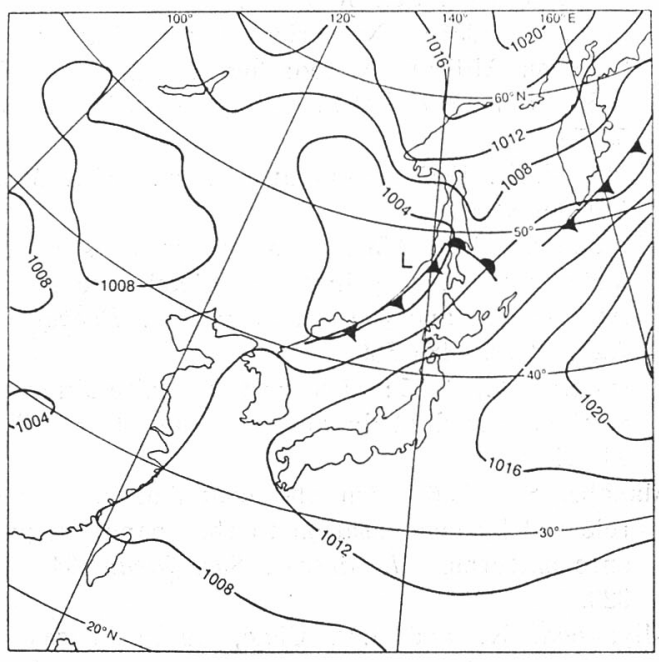

6(a) Observed MSL pressure 1200 GMT 30 July 1986

(a)

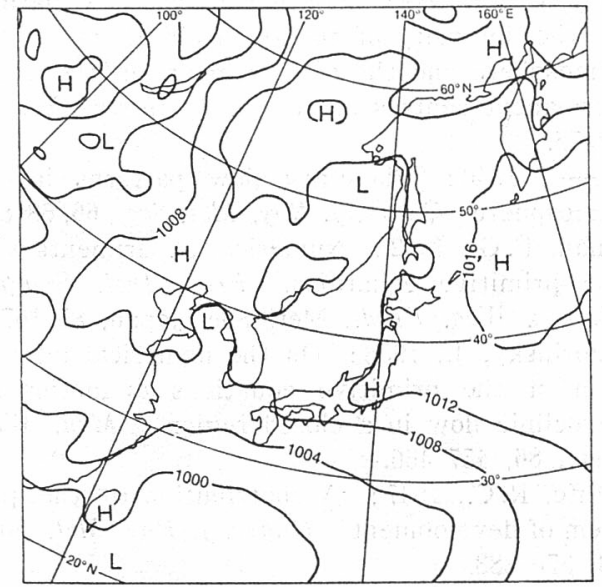

.6(c) ECMWF forecast MSL pressure 1200 GMT 3 August 1986

(c) all the individuals who have contributed to that development. Furthermore, I have not dwelt on recent events as I am sure they will be covered by other speakers at this Symposium. However, It does seem appropriate for me to end with an example of the current state of the art.

In order to be objective about the selection I decided to show two 4-day forecasts for the Japanese Area which verified only 14 hours

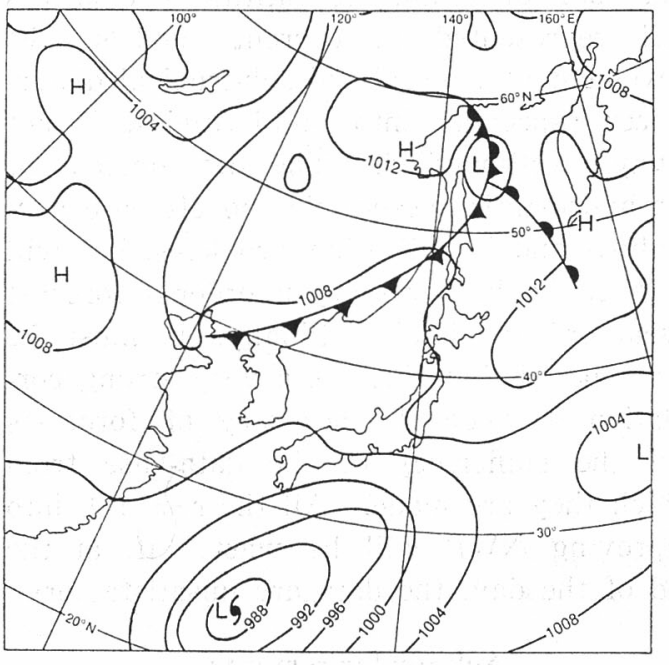

6(b) Observed MSL pressure 1200 GMT 3 August 1986

(b)

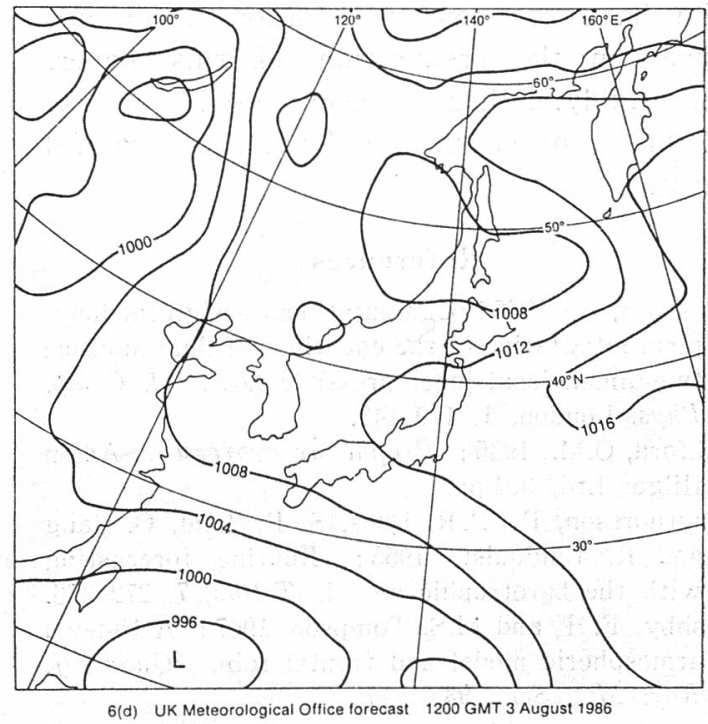

(d)

Fig. 6 a. Actual 1200 GMT 30.7.86

b. Actual 1200 GMT 3.8.86

c. ECMWF Forecast 1200 GMT 3.8.86

d. UK Met Office Forecast 1200 GMT 3.8.86. 
before this presentation was scheduled at the Symposium. One was from ECMWF and the other from the UK Met Office, and these forecasts are shown in Fig. 6. At the time I selected this example I clearly had no information regarding the accuracy of the two forecasts and I leave the reader to make his own assessment of their relative merits (or otherwise).

Much remains to be done. Whilst the behaviour of temperate latitude cyclones is well represented in current models, the movement of tropical and sub-tropical disturbances especially into mid-latitudes, is not always well-handled. The development of non-hydrostatic meso-scale models pose new analysis and initialization problems, but will undoubtedly be necessary in order to forecast "weather" in detail. Finally, it must be remembered that there is a very strong correlation between the accuracy of forecasts and the sufficiency of the data-base from which they are made. All the research into improving NWP will be wasted if, at the end of the day, the data are unsatisfactory.

\section{Acknowledgements}

I wish to thank friends in many countries who have sent me information which has helped in the preparation of this paper. Regrettably, it has not been possible to use all that information, but I am very grateful for it.

\section{References}

Arakawa, A., 1966: Computational design for longterm integration of the equations of fluid motion : two-dimensional incompressible flow. J. Comp. Phys. London, 1, 119-143.

Ashford, O.M., 1985: Prophet or Professor?, Adam Hilger Ltd, 304 pp.

Bergthorsson, P., B. R. Doos, S. Frylund, O. Haug and R. Lindquist, 1955: Routine forecasting with the barotrophic model. Tellus, 7, 272-276.

Bushby, F.H and M.S. Tompson, 1967: A 10-level atmospheric model and frontal rain. Quart. J. Roy. Met. Soc., 93, 1-17.
Charney, J.G., R. Fjørtoft and J. von Neumann, 1950: Numerical integration of the barotropic vorticity equation. Tellus, 2, 237-254.

- , 1955: The use of the primitive equations of motion in numerical prediction. Tellus, 7, 22-26.

Cressman, G.P. and W.E. Hubert, 1957: A study of numerical forecasting errors. Monthly Wea. Rev., 85, 235-242.

Eliassen, A., 1956: A procedure for numerical integration of the primitive equations of the two parameter model of the atmosphere. UCLA Dept. Meteor. Sci. Rept., 4.

Herrlin, O., 1956: Numerical forecasting at the Swedish Military Meteorological Office in 19541956. Bericht des Deutscher Wetterdienstes, 38, $53-55$.

Hinds, M.K., 1981: Computer story. Met. Mag., 110, 69-81.

Hinkelmann, K., 1959: Ein numerisches experiment mid den primitiven gleichungen. The Atmosphere and the sea in motion. Rockefeller Inst. Press, 486-500.

Kasahara, A., 1965: On certain finite-difference methods for fluid dynamics. Mon. Wea. Rev., 93, 27-31.

Manabe, S., 1956: On the contribution of heat released by condensation to the change in pressure patterns. J. Meteor. Soc. Japan, 34, 308320.

Miyakoda, K. and J.P. Chao, 1982: Essay on dynamical long range forecasts of atmospheric circulation. J. Meteor. Soc. Japan, 60, 292-308.

Richardson, L.F., 1922: Weatoer Prediction by Numerical Process. Cambridge University Press, $236 \mathrm{pp}$.

Rossby, C.G., 1939: Relation between variations in the intensity of the zonal circulation of the atmosphere and the displacement of the semipermanent centres of action. J. Marine Res., 2, 38-55.

- 1940: Planetary flow patterns in the atmosphere Quart. J. Roy. Met. Soc., 66, 68-87.

Shuman, F. G., 1962: Numerical experiments with the primitive equations. Proc. Intl. Sympos. Numer. Wea. Pred., Met. Soc. Japan, 85-107.

Smagorinsky, J., 1958: On the nomerical integration of the primitive equations of motion for baroclinic flow in a closed region. Mon. Wea. Rev., 86, 457-466.

Sutcliffe, R. C., 1947: A contribution to the problem of development. Quart. J. Roy. Met. Soc., $73,370-383$. 